\title{
THE EFFECT OF INTER-DEPARTMENTAL SYNERGY ON CONSUMER PURCHASING PATTERN IN AN OMNI-CHANNEL RETAILING ENVIRONMENT IN THE GEORGIAN MARKET
}

\author{
ARIAN MATIN \\ PhD student \\ International Black Sea University, Georgia \\ arianmatin@outlook.com
}

Abstract. This study aims to analyse the impact of the level of synergy in a multi-channel retailer and its end results on customer purchasing behaviour. A deductive approach was adopted by reviewing the past studies on implementation and goals of synergy. It led to a quantitative research model for evaluating the effects of inter-departmental synergy in the market. In order to measure the effect of this strategy on the Georgian customers, a questionnaire was distributed among 412 retail customers. The outcome indicated that the level of synergy positively relates to the frequency and monetary value spent by customers and negatively impacts the threat of pure online retailers as substitutes. The theoretical and managerial implications of the relationship are discussed.

KEYWORDS: INTERDEPARTMENTAL SYNERGY, PURCHASE INTENTION, RETAILING, THE REPUBLIC OF GEORGIA.

For citation: Matin A. (2020). The effect of inter-departmental synergy on consumer purchasing pattern in an Omni-channel retailing environment in the Georgian market. Globalization and Business, №9, pp. 113-119 https://doi.org/10.35945/gb.2020.09.014

\section{INTRODUCTION}

Retailing industry has evolved dramatically in the past couple of decades. The introduction of the internet in the industry, led many firms to adapt their operation in the new environment. The internet impacted the retailers in two main ways, one is in the operational side, by providing a platform for firms to communicate internally and facilitate the movement of products and data between departments.

Moreover, the internet provides a new way of communication and sales to customers. Many multi-channel retailers, today, has replaced the traditional brochures and telemarketing and sales with online outlets and advertising. Consequently, the cooperation between online and offline channels within a retailer can be a significant factor in analysing customer behaviour and elevating their purchase intention.

As mentioned above, inter-departmental synergy can affect the retailer's operations in two ways. Görsch et al. (2001) found that the synergy can impact the operations of a multi-channel retailer all along the vertical chain. On the upstream side, tracking and analysing customer data and transmitting the results back to the suppliers can reduce inventory risks and bullwhip effect. Meanwhile, it can increase efficiency on the downstream side of the market by moving products between outlets. The transfer of products between outlets assist the retailer to adjust the supply in each channel to the demand and prevent lost sales or sales markdowns.

Furthermore, Kollmann et al. (2012) discovered interdepartmental synergy can contribute to implementation of other strategies such as differentiation. His findings point out the synergy can increase customer trust in the retailers operation and help differentiate its services from competitors. Naturally, it requires a comprehensive customer relationship management team in the firm. However, the end result, which is elevating trust and purchase intention, can raise the monetary value spent by customers in each visit.

Although, Beck et al. (2015) explained a proper implementation of inter-departmental strategy is necessary for reaching the end goals of the strategy. He categorized hybrid retailers into three classifications. Multi-channel retailers are the ones with little to no integration between their outlets. The next level is cross-channel retailers with partial integration and communication between their outlets. He called a fully integrated hybrid retailer an Omni-channel retailer. In this case, an Omni-channel retailer is the one capable of implementing the changes necessary to increase the frequency and monetary value of purchases. This study follows the strategies that an Omni-channel retailer can pursue to increase the aforementioned frequency and monetary value of purchases. 


\section{LITERATURE REVIEW}

Interdepartmental synergy adds value to the operation by presenting opportunities for new services within the firm. Steinfield et al. (2013) explained the new services arising from interdepartmental synergy cover the delivery of products in the online and offline channels as well as providing customers with the opportunity to pick up or return the products they purchased online to the nearest offline store.

\section{THE PACE OF DELIVERY AND INTER-CHANNEL PICK-UP AND RETURN POLICY}

The interdepartmental synergy can benefit the retailer in different aspect of their operation. Steinfield et al. (2002) revealed that the synergy can assist Omni-channel retailers in the speed and convenience of orders, added value in product and service customization and in after sale services. In an Omni-channel retailer, interdepartmental synergy assists the channels to communicate and share the routes of the products. It provides the distribution centre the knowledge of where the online orders are supposed to be delivered to. Hence, the centre can add the product purchased by online customer to the daily shipments to the nearest offline store matching the customer's address. Thus, it can cut the time and costs of parallel logistical operation between two channels.

In order to synergize channels across the retailer's operation most effectively, Badrinarayanan et al. (2014) suggests a horizontally spread information technology system, attribute-to-attribute approach and coordinated discount and promotion strategy is indispensable. In this case, there is a need for retailer to adjust the perception of customers and balance it across its channels. Additionally, this harmonization reduces any misconception among customers and enables the retailer to leverage all outlets simultaneously.

Hence, the retailer can reduce the delivery times for its online outlet and implement cross channel pick-up and return policy. Customers can pick-up or return defective products they purchased online to the nearest offline store. Due to inventorial and promotional synchronization across retailer's channels, the costs of product returns and logistics reduce while the repurchase intention among customers elevates.

Meanwhile, customer satisfaction and repurchase intention can be increased by a successful interdepartmental synergy. Cao et al. (2015) proposed the opportunity to crosssell products between the retailer's channels and tracking consumer's information and their conversion rate accelerates the sales and delivery process.

Tracking customer's data assist the managers in understanding their purchasing habits across retailer's outlets. Therefore, managers can adapt the flow of products between channels and the merchandizing mix of each channel optimally. According to Müller et al. (2018), the most effective structure for processing, alteration and flow of information is a horizontal system.

A flat structure facilitates the transmission of information and flow of products between channels. In a centralized hierarchical structure the processing and flow of information can be delayed due to bureaucratic nature of the system. As a result, Omni-channel retailers need to move toward a flat structure to accommodate the necessity of this flow of products and data across their channels.

\section{THE FREQUENCY OF VISITS AND MONETARY VALUE SPENT BY CUSTOMERS}

The purchase intention, the frequency of visits and the monetary value spent by customer can be affected by different factors. Lower prices, quality of products and services and sunk costs can all play a role in the variation in frequency and monetary value of purchases. Nevertheless, interdepartmental synergy can impact them through lowering the price of shipments and added value in pre and post sales services.

Mugaonkar et al. (2011) designed a model for increasing the monetary value spent by customers in a multi-channel retailer. They proposed that the quality of products and services and convenience of purchase can contribute to increasing the money customer is willing to spend in the store. Moreover, they discovered that quality and convenience can shift customers from competitors to the retailer's channels.

As discussed above, interdepartmental synergy provides the retailer with a higher speed of delivery, convenient pickup and return policy for customers and a higher quality of after-sale services. The convenience and speed that the synergy brings along can encourage more spending on the part of customers.

Another aspect of customer purchasing behaviour, as mentioned before, is the frequency of their visits to the stores. Martin et al. (2015) formulated a model for increasing the frequency of purchases and concluded that elements such as control over the purchasing process, trust and ease of use can raise the number of visits customers pay to the store.

Interdepartmental synergy provides convenience in delivery and return for the customers. In addition, it increases the level of control in the purchasing process since customers can freely move the products they purchase between channels and receive the product in the outlet of their choosing.

The segments that the retailer targets, play a significant role in a successful implementation of interdepartmental synergy. Dahana et al. (2019) recommended four different segments for targeting depending on the strategy the retailer pursues. In the case of interdepartmental synergy, the two main segments for the retailer to penetrate, especially in the introduction and early growth stage of their operation, are innovators and integrated shoppers.

Innovators are interested in new trends in shopping and the retailers with up-to-date operations appeal to this section of the market the most. Meanwhile, integrated shoppers, as the name suggests, are customers moving between offline and online outlets. for Omni-channel retailers these two segments have the most potential, offering value added services such as the pick-up and return policies discussed 
earlier can increase the frequency and monetary value of their purchases in high-involvement products.

Lastly, product assortment and price are other factors that can elevate the frequency and monetary value spent by customer through interdepartmental synergy. Chen-Yu and Seock (2002) suggested that price and merchandize mix can increase the frequency of visits and the money customer is willing to spend in the store. As discussed, due to integrated logistics, Omni-channel retailers with deep level of synergy can reduce the variable costs of order processing and delivery in their online outlet and broaden the range of product assortments in their physical stores by intertwining and harmonizing the inventory systems.

There is lack of comprehensive studies in the Georgian market. However, some papers discussed the customers and their purchasing patterns in the market which can shed more light on the effectiveness of interdepartmental synergy among the Georgian customers. Khoshtaria and Matin (2019) found that price, convenience and quality of products and services affect the switching behaviour among the Georgian customers. Their findings indicate a retailer with lower costs of operation or value added products and services are more successful to attract and retain customers in the country.

The lower level of prices and control over the shipment process, as mentioned, are some of the products of interdepartmental synergy. Hence, synergizing channels across an Omni-channel retailer's operation can result in higher market share for the retailer in the Georgian market.

On the side of the retailer, strategic planning can impact the operational efficiency and success in the market immensely. Khoshtaria (2018), researching companies in the Georgian market, concluded that a comprehensive strategic planning can lead to a higher level of performance within the organization and more accurate measurements. It emphasizes the direction this study is taking in evaluating strategic planning and establishing performance indicators from downstream side of the supply chain.

In conclusion, Interdepartmental synergy can benefit Omni-channel retailers in different aspect of their operations. It can contribute to speedy delivery for their online outlets while reducing the costs of logistics. Moreover, the synchronized inventorial and promotional system can broaden the cross and within products assortment in the physical store. These adjustments, in turn, lead to higher level of trust and purchase intention among customers. The elevated level of purchase and repurchase intention results in higher frequency of visits and the monetary value spent by customer in the store.

\section{METHODOLOGY}

This study adopted a deductive approach by reviewing the past studies, exploring interdepartmental synergy and purchase intention among customers. In order to measure the effectiveness of the strategy on customers in the Georgian market, a quantitative method was selected.

This study attempts to analyse the exact variation in the frequency of visits and the monetary value spent by customers in an Omni-channel retailer with regards to the results of interdepartmental synergy. Therefore, a qualitative research will not yield an accurate result in measuring these variations.

\section{RESEARCH OBJECTIVES}

Analysing the past studies, this study attempts to finds the impact of synergy on customer purchasing patterns and whether it reduces the conversion rate of customers to online retailers. Hence, the main objectives of this study are:

- To identify the effects of interdepartmental synergy on customer purchasing pattern;

- To analyse the impact of interdepartmental synergy on the customer's frequency of visits to the store;

- To discover the impact of interdepartmental synergy on the monetary value spent by customer in each visit to the store;

- To evaluate the effect of interdepartmental synergy, as a defensive strategy, in countering the threat of online retailers as substitutes.

\section{RESEARCH QUESTIONS}

In order to explain the relationship between the variables discussed in the literature review, the following research questions need to be answered:

- What is the impact of interdepartmental synergy on customer purchasing behaviour?

- What is the effect of interdepartmental synergy on the frequency of visits paid by customer to the retailer?

- What is the effect of interdepartmental synergy on the monetary value spent by customer on each visit?

- Does the interdepartmental synergy impact the threat of pure online retailer as substitutes?

\section{Formulation hypotheses:}

Based on the models of previous studies and the research questions for this study, the following hypotheses are formulated:

$\mathrm{H} 1$ : Interdepartmental synergy, in an Omni-channel retailer, positively affects the average frequency of visits paid by customers.

$\mathrm{H}$ 2: Interdepartmental synergy, in an Omni-channel retailer, positively affects the average monetary value spent by customers in each visit.

H3: Interdepartmental synergy, in an Omni-channel retailer, negatively affects the threat of pure online retailers as substitutes.

\section{SAMPLING}

To measure the impact of the independent variable (interdepartmental synergy) on the dependent variables (the frequency and monetary value of purchases, threat of online retailers) a questionnaire was designed for the Georgian customers. 
A random sampling method was employed by uploading the questionnaire online. The author then asked random customers in different shopping districts in Tbilisi to fill in the questionnaire on the tablet provided to them.

A total of 412 responses were gathered and analysed. The sample consists of 191 male and 221 female respondents. As for sample age distribution, the highest percentage of respondents was in the age range of 36 to 45 by $28.6 \%$ followed by $21.1 \%$ in the age range of 26 to 35 . The next age group was 45 years or older by $18.2 \%$ and 20 years or younger with $17 \%$ and lastly 21 to 25 with $15 \%$.

The questions were designed on a 5 level Likert scale to measure the impact of independent variable on the dependent ones. The questionnaire was first tested by five respondents before distributing it in the broader public to ensure the questions are understandable. The reliability of the questions and variables are then measured by Cronbach's alpha. The minimum level of 0.7 Cronbach's alpha is considered by Chaiyasoonthorn and Suksa-ngiam (2011) and Khoshtaria (2016) to ensure the variables are reliable.

\section{RELIABILITY OF CONSTRUCT}

\section{For hypothesis H2:}

- H2: Interdepartmental synergy, in an Omni-channel retailer, positively affects the average monetary value spent by customers in each visit.

- Determining variables: the independent variable is the interdepartmental synergy across an Omni-channel retailer's outlet, measured by speed of shipments for online outlet and intertwined pick-up and return policies between channels. The dependant variable is the average of the monetary value spent by customers in the retailer's store.

- Analytical method: in pursuance of testing the $\mathrm{H} 2$ hypothesis, correlation and bivariate regression analysis is utilized due to the fact that one dependent variable is present.

\section{For hypothesis H3:}

- H3: Interdepartmental synergy, in an Omni-channel retailer, negatively affects the threat of pure online retailers as substitutes.

- Determining variables: the independent variable

\begin{tabular}{|l|l|l|}
\hline Questionnaire section & Items & Sources \\
\hline Purchase intention & $\begin{array}{l}\text { Frequency and monetary value of } \\
\text { purchases } \\
\text { Switching to online retailers (negative } \\
\text { relationship }\end{array}$ & $\begin{array}{l}\text { Chaiyasoonthorn and Suksa-ngiam } \\
\text { 2011) } \\
\text { Rose (2012) } \\
\text { Calvo-Porral (2015) }\end{array}$ \\
\hline Interdepartmental synergy & $\begin{array}{l}\text { Speed of delivery } \\
\text { Pick-up and return policies }\end{array}$ & $\begin{array}{l}\text { Kollmann (2012) } \\
\text { Steinfield (2013) } \\
\text { Badrinarayanan (2014) }\end{array}$ \\
\hline $\begin{array}{l}\text { Threat of online retailers as } \\
\text { substitutes }\end{array}$ & $\begin{array}{l}\text { Customers tendency to remain with } \\
\text { the multi-channel retailer }\end{array}$ & $\begin{array}{l}\text { Steinfield (2013) } \\
\text { Machavolu and Raju (2014) } \\
\text { Menon et al. (2018) }\end{array}$ \\
\hline
\end{tabular}

\section{Hypothesis testing and findings:}

The hypotheses formulated for this study attempts to measure the relationship between inter-departmental synergy (I-SYN) on the frequency of visits paid by customers (FRE) and monetary value spent by customers in the store (MV). It also hypothesized that there is a negative relationship between synergy and the threat of online retailers as substitutes (T-ONL).

For hypothesis $\mathrm{H} 1$ :

- H1: Interdepartmental synergy, in an Omni-channel retailer, positively affects the average frequency of visits paid by customers.

- Determining variables: the independent variable is the interdepartmental synergy across an Omni-channel retailer's outlet, measured by speed of shipments for online outlet and intertwined pick-up and return policies between channels. The dependant variable is the average of the frequency of visits paid by customers to the retailer's store.

- Analytical method: in pursuance of testing the $\mathrm{H} 1$ hypothesis, correlation and bivariate regression analysis is utilized due to the fact that one dependent variable is present. is the interdepartmental synergy across an Omni-channel retailer's outlet, measured by speed of shipments for online outlet and intertwined pick-up and return policies between channels. The dependant variable is the threat of online retailers as substitutes measured by the average rate of conversion from Omni-channel and offline outlets to online stores.

- Analytical method: in pursuance of testing the H3 hypothesis, correlation and bivariate regression analysis is utilized due to the fact that one dependent variable is present.

\begin{tabular}{|l|c|c|c|c|}
\hline & I-SYN & FRE & T-ONL & MV \\
\hline I-SYN & 1 & $.848^{* *}$ & $.857^{* *}$ & $.850^{* *}$ \\
\hline FRE & $.848^{* *}$ & 1 & $.889^{* *}$ & $.985^{* *}$ \\
\hline T-ONL & $.857^{* *}$ & $.889^{* *}$ & 1 & $.891^{* *}$ \\
\hline MV & $.850^{* *}$ & $.985^{* *}$ & $.891^{* *}$ & 1 \\
\hline
\end{tabular}

Correlation is significant at the 0.01 level (2-tailed). ** 
As it is evident from the table above, interdepartmental synergy has significant relationships with the frequency of visits by customers (.848), the monetary value of purchases (.850) and countering the threat of online retailers as substitutes (.857).

MODEL SUMMARY OF BIVARIATE LINEAR REGRESSION ANALYSIS FOR H1, H2 AND H3

\section{INTERPRETATION OF RESULTS}

The end results of interdepartmental synergy vary based on the goal of the retailer and the manner in which the strategy is implemented. The strategy can bring extra fixed costs for retailer due to its requirements for successful implementation. The retailers should employ a horizontally spread customer relationship management to supervise the

\begin{tabular}{|l|r|r|r|r|l|l|}
\hline Model & \multicolumn{1}{|l|}{ Dependent } & \multicolumn{1}{|c|}{ R square } & \multicolumn{1}{c|}{ F } & Beta & \multicolumn{1}{c|}{ t } & Sig. \\
\hline \multirow{3}{*}{$\begin{array}{l}\text { Interdepartmental Synergy } \\
\text { (I-SYN) (independent) }\end{array}$} & (FRE) & .718 & 1047.794 & .848 & $\begin{array}{l}.007 \\
32.370\end{array}$ & .000 \\
\cline { 2 - 7 } & (MV) & .723 & 1071.711 & .850 & $\begin{array}{l}.068 \\
32.737\end{array}$ & .000 \\
\cline { 2 - 7 } & (T-ONL) & .735 & 1138.052 & .857 & $\begin{array}{l}4.452 \\
33.735\end{array}$ & .000 \\
\hline
\end{tabular}

Dependent variables: frequency of purchases, the monetary value of purchases, the threat of online retailers.

In $\mathrm{H} 1$ hypothesis the $\mathrm{F}$ score is high and simultaneously significance is less than .005 while R square stands at .718. The results indicate that interdepartmental synergy explains the variability in the frequency of purchases by $71.8 \%$.

The correlation between the variables is positive which reveals implementing interdepartmental synergy efficiently can elevate the frequency of purchases in the Omni-channel retailing environment.

In $\mathrm{H} 2$ hypothesis the $\mathrm{F}$ score is high and simultaneously significance is less than .005 while R square came at .723. The results indicate that interdepartmental synergy explains the variability in the monetary value of purchases by $72.3 \%$.

The correlation between the variables is positive which reveals implementing interdepartmental synergy efficiently can elevate the monetary value of purchases in the Omnichannel retailing environment.

Finally, following the same line of calculations, in $\mathrm{H} 3$ hypothesis the $\mathrm{F}$ score is high and simultaneously significance is less than .005 while $R$ square came at .735 . The results indicate that interdepartmental synergy explains the variability in the monetary value of purchases by $73.5 \%$.

The correlation between the variables is positive which reveals implementing interdepartmental synergy increases the tendency of customers to remain with the retailer rather than switching to online retailers. As a result, the threat of online retailers as a substitute to multi-channel retailers reduces by implementing a successful interdepartmental synergy.

\section{RELIABILITY OF MEASURES}

As discussed above, in order to confirm the reliability of the variables in the research construct, Cronbach's alpha level of 0.7 is considered acceptable. The following is the Cronbach`s alpha for this study. flow of information and products within the firm. Moreover, the information technology to connect all the data from different departments and receipts and addressed from customers may increase the initial capital investments.

In the case of a retailer seeking to increase the frequency of customers visits, harmonized inventories to keep the product assortments balanced across all channels is necessary. Rising frequency may lead to disparity in the inventories. Since customers purchase high-involvement products in specific trends such as seasonality, fashion ability and brand equity. This trend in purchases may cause one product to sell quickly while others remain in the inventories for a while. Hence, retailers need to keep track and balance their inventories in case of rising frequency of purchases.

On the other hand, if the goal is to raise the monetary value of customers only, the firm needs to elevate their products and services on quality/price curve. In this case, customer relationship management will play a significant role as well as the suppliers. Customers in this sector are willing to pay more to purchase products from high-end brands and expect a high quality of services.

The most straightforward path, for the retailers appealing to customers in this segment, is a vertical alliance with their suppliers so that integrating customer relationship management and product updates and presales can be conducted by the retailer on their offline and online outlets.

Lastly, online retailers' main characteristics which propelled them to success in the last two decades are lower prices and convenience and control over the ordering

\begin{tabular}{|l|l|}
\hline Variable & Cronbach`s alpha \\
\hline $\begin{array}{l}\text { Interdepartmental } \\
\text { synergy }\end{array}$ & .842 \\
\hline $\begin{array}{l}\text { Frequency of visits by } \\
\text { customers }\end{array}$ & .987 \\
\hline $\begin{array}{l}\text { Monetary value spent by } \\
\text { customers }\end{array}$ & .984 \\
\hline $\begin{array}{l}\text { Threat of online retailers } \\
\text { as substitutes }\end{array}$ & .891 \\
\hline
\end{tabular}


process. Online retailers low fixed costs contributed to lower end prices for customers and the fact that they are always available for customers to place orders in at any time and any place assisted them in gaining market share.

For Omni-channel retailer with a proper interdepartmental synergy, the variables costs of order processing and deliveries reduces. It makes them competitive in the pricing for customers with pure internet retailers. Secondly, Omni-channel retailers can utilize their online outlets to solve the availability of services issue that brick-and-mortar retailers face and compete with online retailers in the ease of use and control parameters.

\section{CONCLUSION}

This study aimed to measure the impact of interdepartmental synergy for Omni-channel retailers on customer purchasing patterns and find ways for them to expand in the market. the main products of a successful implementation of interdepartmental synergy, as discussed, are faster delivery with lower costs for the online outlet and inter-channel pick-up and return policies.

These advantages, as hypothesised, can encourage customers to visit the stores more frequently and spend more money on average in each visit. The study adapted a quantitative method to measure these links in Georgia by selecting a random sampling of retail customers in Tbilisi.

The results indicated that Georgian customers are willing to visit an Omni-channel retailer and increase the monetary value of their purchases provided that faster delivery and interchannel pick-up and return policies are practiced effectively in the store. In summary, a successful implementation of an Omni-channel operation in Georgia can encourage customers to visit the retailer and elevate their monetary value of purchases, however, it requires the retailer to increase its initial investments across channels and run a horizontal and efficient customer relationship management.

\section{THEORETICAL AND PRACTICAL VALUES}

The model designed in this study is a combination of different researches conducted previously in other markets. There is a lack of studies on the Georgian market and how customers react to different strategies. Multi-channel retailing is a new phenomenon in the country and there are no researches evaluating this type of operation in the market.
Another theoretical value of this study is in its model. The construct measures the success of the strategy from downstream side of the supply chain and trace it back to upstream. Most of traditional models analyse the impact of strategy from managers and suppliers in upstream side and extend it to customers. However, this paper measures the end results of the strategy through customer responses and then builds a path toward planning and implementation of the strategy.

On the practical side, it provides managers with a framework to implement an appropriate interdepartmental synergy towards specific goals to increase customer's purchase intention. Since the customers in the Georgian market are the respondents, the manager's tasks is to link their operations to the needs of customers.

Finally, through the elements explained in the study, managers can arrange their operations and allocate their resources with regards to their online and offline outlets and their distribution centres to ensure the flow of products and information between their channels.

\section{LIMITATIONS OF THE STUDY}

The main limitation of the study is that multi-channel retailing is a new phenomenon in Georgia and, hence, these types of retailers only operate in Tbilisi and few other cities. There is no wide spread use of online or multi-channel retailers in rural areas in the country. As a result, the reactions of residences in rural areas cannot be included.

Subsequently, since multi-channel retailing is in its introduction phase in Georgia, there is a lack of international retailers in the market. Global retailers are usually working with a third party to deliver their orders to the Georgian market. Therefore, respondents are not completely familiar with a fully operational Omni-channel retailer as is the case for the Western Europe or the United stated.

\section{RECOMMENDATIONS FOR FURTHER RESEARCH}

For future studies, the author recommends testing the variables on a broader target market. This research was limited to customers in Tbilisi and covering the rural areas can yield new results. Furthermore, another study that analyses the end results of other strategies in multi-channel retailing environment on customers can be useful for managers in the industry and researchers.

\section{REFERENCES}

Badrinarayanan, V., Becerra, E., \& Madhavaram, S. (2014). Influence of Congruity in Store-Attribute Dimensions and SelfImage on Purchase Intentions in Online Stores of Multichannel Retailers . Journal of Retailing and Consumer Services , 21 (6), 1013-1020.

Beck, N., \& Rygl, D. (2015). Categorization of multiple channel retailing in Multi-, Cross-, and Omni-Channel Retailing for retailers and retailing. Journal of Retailing and Consumer Services , 27 (1), 170-178.

Calvo Porral, C., Martínez Fernández, V., Juanatey Boga, O., \& Lévy Mangín, J. (2015). Measuring the influence of customerbased store brand equity in the purchase intention. Cuadernos de Gestión , 15 (1), 93-118.

Cao, L., \& Li, L. (2015). The Impact of Cross-Channel Integration on Retailers' Sales Growth. Journal of Retailing , 91 (2), $198-216$. 
Chaiyasoonthorn, W., \& Suksa-ngiam, W. (2011). Factors Influencing Store Patronage: A Study of Modern Retailers in Bangkok Thailand . International Journal of Trade, Economics and Finance , 2 (6), 520-526.

Chen-Yu, J., \& Seock, Y. (2002). Adolescents' Clothing Purchase Motivations, Information Sources, and Store Selection Criteria: A Comparison of Male/Female and Impulse/Nonimpulse Shoppers. Family and Consumer Sciences Research Journal , 31 (1), 50-77.

Dahana, W., Miwa, Y., \& Morisada, M. (2019). Linking lifestyle to customer lifetime value:An exploratory study in an online fashion retail market. Journal of Business Research , 99, 319-331.

Görsch, D. (2001). Do Hybrid Retailers Benefit from the Coordination of Electronic and Physical Channels? . 9th European Conference on Information Systems. Bled: European Conference on Information Systems.

Khoshtaria, T. (2016). Strategic Processes in Georgian Manufacturing Companies - Business-Level Strategy Perspective. Seria: Administracja i Zarządzanie , 36, 47-73.

Khoshtaria, T. (2018). The Impact of Strategic Planning on Organizational Performance Through Strategy Implementation. Globalization And Business , 5, 84-89.

Khoshtaria, T., \& Matin, A. (2019). Qualitative investigation into consumer motivations and attitudes towards research shopping in the Georgian market. Administration and Management , 48, 41-52.

Kollmann, T., Kuckertz, A., \& Kayser, I. (2012). Cannibalization or synergy? Consumers' channel selection in online-offline multichannel systems . Journal of Retailing and Consumer Services , 19 (1), 186-194.

Machavolu, S., \& Raju, K. (2014). Showrooming: The Next Threat to Indian Retail. International Journal of Business Research , 1 (1), 1-14.

Martin, J., Mortimer, G., \& Andrews, L. (2015). Re-examining online customer experience to include purchase frequency and perceived risk. Journal of Retailing and Consumer Services, 25, 81-95.

Menon, P., Barani, G., \& Suganthalakshmi, T. (2018). Mapping Customer Shopping Attitude Towards Webrooming Technique. International Journal of Pure and Applied Mathematics, 119 (12), 991-1003.

Mugaonkar, P., Ananthan, P., Samal, S., \& Debnath, B. (2011). A Study on Consumer Behaviour at Organized Fish Retail Outlet. Agricultural Economics Research Review , 24, 133-140.

Müller, R., Sankaran, S., Drouin, N., Vaagaasar, A., Bekker, M., \& Jain, K. (2018). A theory framework for balancing vertical and horizontal leadership in projects. International Journal of Project Management, 36 (1), 83-94.

Rose, S., Clark, M., Samouel, P., \& Hair, N. (2012). Online Customer Experience in e-Retailing: An empirical model of Antecedents and Outcomes. Journal Of Retailing , 88 (2), 308-322.

Steinfield, C., Adelaar, T., \& Lai, Y. (2002). Integrating Brick and Mortar Locations with E-Commerce: Understanding Synergy Opportunities1. The 35th Annual Hawai'i International Conference on System Sciences (pp. 10-20). Big Island, Hawaii: The Hawai'i International Conference on System Sciences.

Steinfield, C., Bouwman, H., \& Adelaar, T. (2002). The Dynamics of Click-and-Mortar Electronic Commerce: Opportunities and Management Strategies. International Journal of Electronic Commerce , 7 (1), 93-119. 